\title{
A PÓS-GRADUAÇÃO STRICTO SENSU EM ENFERMAGEM E A FORMAÇÃO DE PESQUISADORES
}

Eliete Albano de Azevedo Guimarães - Doutora em Ciências da Saúde. Professora Adjunta da Universidade Federal de São João delRei (UFSJ). Coordenadora do Programa de Pós-Graduação em Enfermagem da UFSJ. Líder do Núcleo de Estudos e Pesquisas em Avaliação e Gestão de Serviços de Saúde (NEPAG), e-mail: elietealbano@ufsj.edu.br

Tarcísio Laerte Gontijo - Doutor em Ciências da Saúde. Professor adjunto do curso de Enfermagem da Universidade Federal de São João del-Rei (UFSJ). Vice-Coordenador do Programa de Pós-Graduação em Enfermagem da UFSJ, e-mail: enftarcisio@ufsj.edu.br

Samuel Barroso Rodrigues - Pós-doutorando em Saúde Coletiva. Doutor em Enfermagem Psiquiátrica. Professor da Universidade do Estado de Minas Gerais (UEMG). Professor Auxiliar I da Universidade de Itaúna, e-mail: samuelbarroso88@gmail.com

Historicamente a Enfermagem é reconhecida como prática social relacionada à prestação de cuidados que abrange as diferentes dimensões do ser humano, tanto no âmbito individual quanto coletivo, incluindo o compromisso com a sua integralidade em suas distintas complexidades ${ }^{(1)}$.

No entanto, nas últimas décadas, tal enfoque tem se ampliado, à medida que, ao incorporar-se de conceitos mais complexos e holísticos, a Enfermagem necessita estabelecer estratégias inovadoras, para que a promoção de mudanças em sua prática, seja condizente às novas realidades de pensamento, tecnologias e transformações sociais(2).

Este processo engendra a busca por práticas mais efetivas e concretas de produção e disseminação do conhecimento, sobretudo, capazes de articular as potencialidades de enfrentamento das diversidades que circundam o saber da profissão. Procura-se, ainda, estabelecer relações causais, embasadas no saber científico e ancoradas em perspectivas construtivistas e de natureza interdisciplinar ${ }^{(3)}$.

Dadas as características do campo de conhecimento da Enfermagem, percebe-se que a PósGraduação em Enfermagem, no Brasil, encontra-se em grande expansão, constatada pelo aumento do número de cursos e programas, de egressos e da produtividade científica com publicação de artigos em periódicos de impacto na área. Apesar de os avanços, entende-se, portanto que tal ampliação não vem atingindo todo o país de forma homogênea, uma vez que, para além da região Sudeste, há locais desprovidos de programas de incentivo e carentes de doutores em enfermagem. De 2014 a 2016, por exemplo, houve decréscimo na proporção de cursos, principalmente, na região Sudeste.

O país hoje conta com 75 programas de Pós-Graduação Stricto Sensu em Enfermagem, credenciados pela CAPES, sendo 42 cursos de Mestrado Acadêmico, 24 Cursos de Doutorado e nove na modalidade de Mestrado Profissional. No estado de Minas Gerais, existem apenas cinco cursos de Mestrado Acadêmico em Enfermagem (UFMG, UFTM, UFJF, UFSJ e UNIFAL) e três cursos de Doutorado em Enfermagem (UFMG, UFTM, UNIFAL), número insuficiente para a formação de enfermeiros pesquisadores no Estado. 
Entre as dificuldades e preocupação com a área, destaca-se a sustentabilidade desses Programas, pelo fato, principalmente, de ausência de financiamento regular. De forma equivalente à necessidade de estabelecimento de um orçamento condizente à promoção da pesquisa, de forma expansiva e equânime, salienta-se a importância de se incitar a reflexão dos valores agregados à autoridade da prática investigativa e do saber científico na transformação da prática social. Neste ínterim, o desenvolvimento sustentável de Programas de Pós-Graduação em Enfermagem é imprescindível para a formação de enfermeiros pesquisadores capazes de produzir e disseminar conhecimento quanto à diversidade, ao livre debate de ideias, à elevação da qualidade de vida e saúde e à efetivação do exercício da cidadania.

A Enfermagem tem melhorado e vem se sustentando, enquanto profissão alicerçada na ciência, pela busca de inovações tecnológicas ao cuidado em saúde e ao crescimento social. Sua visibilidade e inserção internacional, do mesmo modo, gradativamente, vêm ocupando espaços por experiências e projetos colaborativos da maior relevância, para a sua qualificação, em nível avançado, com o intuito de elevar a qualidade de vida e saúde da população e o destaque científico de nosso país.

Com base em avanços e desafios da Pós-Graduação na Área de Enfermagem, vislumbra-se uma expansão qualitativa desse curso com redução das assimetrias regionais, uma maior visibilidade regional e nacional da profissão enquanto produtora de conhecimento, a fim de que haja, em consequência, maior qualificação dos profissionais inseridos no mercado de trabalho com desenvolvimento de tecnologia e inovação e a consolidação das premissas básicas do Sistema Único de Saúde (SUS), de forma a contribuir com a capacitação de recursos humanos, inovação e práticas multi e interdisciplinares ao cuidado individual e coletivo à saúde humana e à gestão de serviços de saúde.

\section{REFERÊNCIAS}

1. Oliveira DC, Ramos FRS, Barros ALBL, Nóbrega MML. Classificação das áreas de conhecimento do CNPq e o campo da Enfermagem: possibilidades e limites. Rev Bras de Enf. 2013;66:60-5.

2. Ferreira RE, Tavares, CMM, Santos, GSS, Fonseca PIMN. Motivação do enfermeiro para ingressar em uma pós-graduação stricto sensu. Rev Baiana de Enf, 2015; 29(2):180-5.

3. Sochi CGS, Munari DB, Gelbcke FL, Erdmann AL, Guitiérrez MGR, Rodrigues RAP. Pós-graduação stricto sensu em enfermagem no Brasil: avanços e perspectivas. Rev Bras Enferm, 2013; 66: 80-9.

4. Silva PP, Oliveira MDS, Spindola T, Xavier ML, Oliveira, DCD, Franco VQ. Dissertações de mestrado em enfermagem. Rev enferm UERJ, 2016; 24(4):e18407. 